\title{
Unable to Obtain Satisfactory Vascular Access
}

National Cancer Institute

\section{Source}

National Cancer Institute. Unable to Obtain Satisfactory Vascular Access. NCI Thesaurus.

Code C100027.

The coronary sinus / left ventricular lead was not implanted because the operator was

unable to obtain satisfactory vascular access. (ACC) 